(as shown in Fig. 1) a faint surface of demarcation appears, constituting the boundary between liquid and gas, but at first wholly devoid of curvature. We must, however, take care not to suppose that a cloud necessarily precedes the formation of true liquid. If the pressure be sufficiently great, no cloud of any kind will form."

After describing the results obtained by the lecturer with carbonic acid under varied conditions of temperature and pressure, of which a full account has already appeared in NATURE, * Dr. Andrews remarked that it would be erroneous to say that between liquid and gas there exists one intermediate state of matter, but that it is correct to say that between ordinary liquid and ordinary gas there is an infinite number of intermediate conditions of matter, establishing perfect continuity between the two states. Under great pressures the passage from the liquid to the gaseous state is effected on the application of heat without any break or breach of continuity. A solid model, constructed by Prof. J. Thomson, from the data furnished by the experiments of the lecturer, exhibited very clearly the different paths which connect the liquid and gaseous states, showing the ordinary passage by break from the liquid, as well as the continuous passages above the critical point.

After referring to the experiments of Frankland on the change produced by pressure in the spectrum of hydrogen, and to those of the same able chemist and Lockyer on the spectrum of the spark in compressed gases, Dr. Andrews described the remarkable change from a translucent to an opaque body, which occurs when bromine is heated above the critical point; and then drew attention to the general fact that when the critical point is reached, the density of the liquid and gas become identical.

In order to establish the continuity of the solid and liquid states, it would be necessary in like manner, by the combined action of heat and pressure, to obtain the solid and liquid of the same density and of like physical properties. To accomplish this result would probably require pressures far beyond any which can be reached in transparent tubes, but future experiment may show that the solid and liquid can be made to approach to the required conditions.

\section{ON AN ADDITIONAL TRUE RIB IN THE HUMAN SUBҰECT}

$7 \mathrm{HE}$ almost absolute rule that there are seven true ribs in the human subject has, like every other rule, its exceptions. Occasionally instances are met with in which there are eight sternal ribs on one or both sides. But Nature does not effect her evolutions by per saltum transitions between extreme points, but steadily makes progress by degrees almost imperceptible to human intelligence. So in the matter of rib transition, there are various grades met with between the presence of a complete eighth sternal rib on the one hand, and its absence on the other. In the sternum of a female subject recently dissected at the Royal College of Surgeons, the right seventh and eighth rib cartilages blended together about a quarter of an inch distant from the mesosternum. On the left side the eighth rib cartilage was arrested about an inch and a half from the mesosternum. The latter was free at its sternal end. In another subject-a moderately muscular male-the eighth rib cartilage on the right side extended within an inch of the mesosternum, its extremity being free. On the left it was aborted at the distance of two and a half inches from the mesosternum. In the latter subject the sternum was exceedingly large; all the rib cartilages, especially the seventh on the left side, were well developed, and the xiphisternum was very much elongated, spatulate, and curved in an anterior direction. Occasionally specimens are met with in which the sixth rib cartilage is implanted upon the distal extremity of the mesosternum (rather than upon its distal lateral aspect), lying in front of the xiphisternum, and separated from its fellow of the opposite side by a small interval. In the receding angle formed by their divergence, the seventh sternal ribs are placed, lying directly upon the xiphisternum, and articulating with it, barely attaining an attachment to the mesosternum. This closely simulates the arrangement met with when the eighth sternal rib is present.

In another adult male skeleton, I found a complete specimen of an eighth sternal rib, but only on the right side. It articulated with the xiphisternum, and not with the mesosternum. On the left side the seventh sternal rib cartilage was larger than the corresponding one on the right side, and articulated with both the mesosternum and xiphisternum.*

On examining the skeletons (human) in the Hunterian Museum, I noticed another instance of an eighth sternal rib in an adult male African negro, occurring on the right side only. It was in every respect similar to the preceding. This is the only instance out of the fifteen skeletons (human) contained in the museum which deviated from the average standard number of seven true ribs. It is just possible that it may be more frequently present and remain undetected. In maceration the cartilages are very frequently removed, and articulators prepare artificial ones in their place corresponding to the average seven.

On examining the higher quadrumana, \&c., I noticed that this additional true rib was present only in one young chimpanzee, but not in the gorillas and orangs. It was present in the gibbon and silvery gibbon, the pig-tailed monkey, Macacus Rhesus, Galeopithecus, and Indri. The ayeaye, the slender lemur, and the squirrel monkey, have each nine true ribs. The grand galago, the awantilo, the slender loris, the douroucouli, and the potto, have each ten true ribs. Prof. Flower very kindly called my attention to a paper on the axial skeleton of the Primates by Mr. St. George Mivart, $\phi$ in which these rib variations are described as follows: - "In the highest forms of the Primates, the number of true ribs is seven, but in Hylobates there are sometimes eight pairs. In Semnopithecus and Colobus there are generally seven, but sometimes eight pairs of true ribs. In the Cynopithecinæ the normal number is eight. In the Cebidæ there are generally seven or eight pairs, but in Ateles sometimes nine. In Hapale there are sometimes as few as six, sometimes as many as eight; seven or eight in Galago, Lemur, and Indris; nine in Cheiromys. The highest number, as might be expected, is found in the Nycticebinæ, there being as many as ten pairs of true ribs in Perodicticus and Loris."

Professor Flower remarks " that "in the higher Simiina the ribs do not differ very notably from those of man, except in number; but in the lower forms, and especially in the Lemurina, they more resemble those of the Carnivora."

In the Carnivora the number of nine sternal ribs is fairly constant. There are some exceptions, however, e.g. the Esquimaux dog-the Arctic wolf and Proteles have only eight true ribs. The common badger (Meles taxus) has ten true ribs - the tenth rib being implanted on the apex of the xiphisternum. The ninth rib in all these animals is more or less intimately associated with the xiphisternum, but rarely forming so decided an articulation with it as in the badger.

In a dog's sternum lately in my possession, the xiphisternum had the ninth rib articulated directly with it.

* This does not obviate the rule laid cown by Prof. Flower in his recent admirable book on the Osteology of the Mammalia, that the xiphisternum never carries any true ribs. This is the average rule. But variations are frequent, although they cannot be considered in a text-book on average, and notirregular, Osteology.

$\dagger$ Proceedings of the Zoological Society of London June $27, \mathbf{1 8 6 5 .}$

+ Osteology of the Mammalia, p. 89 . 
The former (xiphisternum) was bifid through its whole length.

The scientific value of this additional sternal rib-in a Darwinian sense-is simply great. It evinces in a clear and forcible manner a latent disposition in the human subject, either to revert to an original and lower condition, or to retain traces of that previous condition. We have already seen that some of the lowest forms of Primates have ten true ribs, others have nine, some eight, and others again seven, as in the human subject. But it is interesting, indeed, to find that the conflict between the major number ten and the minor seven takes place in the lower Primates. As we pass up to the higher Primates, there seems to be a decided tendency towards fixity at the number of seven true ribs. But yet a few solitary examples-besides the human subject-illustrate the lower type, as in the chimpanzee already mentioned. The number of ribs in the lower forms of monkeys seems to be a repetition of that in the Carnivora, and subject to the same fluctuations between seven and ten true ribs. Although the few specimens which I have examined of the higher Primates show a decided tendency towards fixity at the number of seven, yet I believe that in a very large number of skeletons of each of the higher species, various transitional grades would be met with closely according with those in the human subject. It is somewhat remarkable that each of the variations of the eighth rib in the human subject which I have described should all be on the right side.

From the preceding facts it may be decidedly inferred that the tenth, ninth, and eighth true ribs are gradually lost in the transition from the lower to the higher Primates, except in a few isolated examples. The recurrence of the eighth true rib in the human subject cannot be looked upon as an accident, any more than the presence of a distinct peroneus quartus, and a moderately large extensor primi internodii hallucis coming from the tibialis anticus, exactly as in the chimpanzee, in the same individual whose sternum, with an almost complete eighth rib, has been described.

J. BESWICK-PERRIN

\section{NOTES}

THE men of the North do not seem disposed to let grass grow under their feet in respect to their proposed College of Ihys:cal Science, at Irewrcastle-upon-Tyne. Of the 35,000 . required, in addition to to the Durham University endowment, to carry out their plans, upwards of $23,600 \%$. has been already subscribed. Three of the professorial chairs have now been filled, viz. :-Experimental Physics: A. S. Herschel, M.A. Chemistry: A. Freire-Marreco, M.A. Geology: David Page, LL.D., F.R.S.E. No decision has yet been made public in respect to the professorship of Mathematics. This appointment, together with the chair of Experimental Physics, is in the hands of the Dean and Chapter of Durham. These selections will give general satisfaction, and are sufficient assurance of the desire of the Committee to obtain the services of the men within reach, without reference to local influence or predilections. Indeed it seems to us just possible that the claims of one eminent local geologist may have suffered somewhat through the fear of a charge of partiality. Few family names stand higlier in the scientific world than that of Herschel, and its present representative is well known as a teacher of experimental philosophy. M. Freire-Marreco has long served the University of Durham as its reader in chemistry and the Newcastle College of Medicine as its lecturer. Apart from his acquirements as a chemist and his ability as a teacher, there is perlaps no one who is so thoroughly versed in the chemical teclinology of the industries of the North of England. Dr. Paje's elementary worlss on geology are widely appreciated, and if one may judge of his capacity as a lecturer by his power of interesting a general audience, he is eminently fitted to instruct the rising generation of mining engineers. We learn that the opening of the College is fixed for October 7 , and shall watch with pleasure the progress of the undertaking, bidding it heartily "God speed."

A $\mathrm{T}$ a meeting of the Council of University College, London, held on Saturday last, a scheme for the establishment of a Sharpey Physiological Scholarship in the College was adopted. It is expected that the annual value of the Scholarship will be about $100 \%$.

Sir Dominic Corrigan, Bart, M.D., M.P., has been ap. pointed Vice-Chancellor of the Queen's University in Ireland, in the room of the late Sir Maziere Brady, Bart.

ONLY one gentleman has this year obtained the degree of D.Sc. of the University of London, Mr. W. A. Tilden, in Chemistry.

M. H. Sarnte-Clatr-Deville, one of the most leamed and popular members of the Institute, was a candidate at the recent French election on the moderate Republican ticket. M. Broca, the celebrated anthropologist, who will soon be a member of the Institute, was also a candidate on the same ticket, as was also M. Wolowsky, a member of the Académie des Sciences Morales et Politiques. We learn that M. Wolowski has been returned at the head of the poll, and that MM. Scheurer-Restner and Laboulaye have also been elected for Paris. The Institute is fast becoming, not actually a political body, but a body more closely connected with politics than it was formerly. For some time past a részumé of the sittings of the Academy has been inserted regularly in the Fournal Officiel, which is becoming every day more scientific in its character. The National Society of Men of Letters recently held its ordinary meeting, when it was proposed to erase from ts list of members MM. Victor Hugo, Pyat, and Rochefort, who are being prosecuted for their deeds during the Commune. But the meeting rejected the motion.

THe Revue des Cours Scientifiques commences with July I a new series, with the new title La Revue Scientifique, under the old editorship of MM. Yung and Alglave. The first number of the new series contains a sketch of the labours of the late $M$. Claparède, translations of Profs. Huxley and Tyndall's addresses at the Liverpool meeting of the British Association, and some fresh notes by Prof. Van Beneden on Commensalism in the Animal Kingdom.

THE weekly journal, L'Institut, has just entered on the fortieth year of its existence.

Herr RüMKer has communicated to the Asirononische Nachrichten the following ephemeris of a new comet discovered by Temple on the i4th ult, ol Beri.in Mean Time.

$$
\text { R. A. N. Decl. }
$$

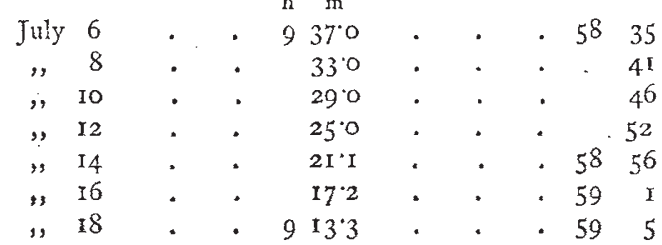

AT the Anniversary Meeting of the Meteorological Society, held June 21, C. W. Walker, Esq., F.R.S., F.R.A.S., the president, in the chair, the following officers were elected :-President : Dr. John W. Tripe. Vice-Presidents: N. Beardmore, C. O. F. Cator, G. J. Symons, C. V. Walker, F.R.S. Treasurer : H. Perigal. Trustees: Sir Antonio Brady, S. W. Silver. Secretaries: Chas. Brooke, F.R.S., Jas. Glaisher, F.R.S. Foreign Secretary: Lieut.-Col. Alexander Strange, F.R.S. 